OPEN ACCESS

Edited by:

David Pérez-Jorge,

University of La Laguna, Spain

Reviewed by:

Silvio lonta,

University of Lausanne, Switzerland

Eva Ariño Mateo,

Universidad Europea de Valencia,

Spain

*Correspondence:

Angeliki Kallitsoglou

angeliki.kallitsoglou@roehampton.

ac.uk

Specialty section

This article was submitted to

Special Educational Needs,

a section of the journal

Frontiers in Education

Received: 18 December 2021

Accepted: 18 January 2022

Published: 14 February 2022

Citation:

Morgül E, Kallitsoglou A, Essau CA and Castro-Kemp S (2022)

Caregiver-Reported Changes in the Socioemotional Wellbeing and Daily Habits of Children With Special Educational Needs During the First COVID-19 National Lockdown in the United Kingdom.

Front. Educ. 7:838938. doi: 10.3389/feduc.2022.838938

\section{Caregiver-Reported Changes in the Socioemotional Wellbeing and Daily Habits of Children With Special Educational Needs During the First COVID-19 National Lockdown in the United Kingdom}

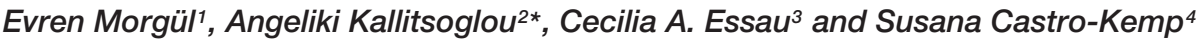 \\ ${ }^{1}$ Department of Psychology, University of Roehampton, London, United Kingdom, ${ }^{2}$ School of Education, University \\ of Roehampton, London, United Kingdom, ${ }^{3}$ Department of Psychology, University of Roehampton, London, \\ United Kingdom, ${ }^{4}$ Department of Psychology and Human Development, IOE, UCL's Faculty of Education and Society, \\ London, United Kingdom
}

The implementation of social distancing measures (e.g., school closures) by governments worldwide to prevent the spread of COVID-19 has affected millions of children and their families. However, the consequences of such measures on the wellbeing of children with special educational needs (SEN) and their caregivers are not fully understood. The present study examined the socioemotional wellbeing and daily habits of children between 5 and 12 years old with SEN during the first national COVID19 lockdown in the United Kingdom. Participants were 995 caregivers between 18 and 61 years old living in the United Kingdom who completed a 20 -min electronic survey on child and family wellbeing distributed via social networks between July and August 2020. The findings showed that children with SEN were more likely to experience more emotional and behavioral difficulties during the lockdown than children without SEN. Children with SEN but without mental health difficulties did not have more behavior difficulties during the lockdown than children without SEN. There was a significant increase in screen time and decrease in sleep time for children with and without SEN during the lockdown, but children with SEN were using screens more often than children without SEN both before and during the lockdown. Finally, caregivers with children with SEN reported more difficulty with the confinement than caregivers with children without SEN, but caregiver and child poor mental health were likely to explain the difference. The findings show that the wellbeing of children with SEN was more likely to be negatively affected by the lockdown than the wellbeing of children without SEN. Caregiver and child mental health were likely to explain the differences.

Keywords: special educational needs (SEN), COVID-19, child mental health and wellbeing, caregiver mental health, internalizing and externalizing symptoms, daily habits, screen time, physical activity 


\section{INTRODUCTION}

The coronavirus disease-2019 (COVID-19) pandemic has had an unprecedented impact on children and families across the world. To cope with the rapid spread of the disease, governments worldwide implemented wide-ranging public health measures including lockdowns and school closures. The United Kingdom (UK) has been one of the seriously affected countries, which led the government to implement the first national lockdown in March 2020 to slow the spread of the coronavirus (Worldometer, 2020). The lockdown resulted in school closures for all children except for vulnerable children and children of keyworkers. School closures resulted in extensive disruption to the psychological, academic, and social lives of children and young people (Holmes et al., 2020; Creswell et al., 2021; Panchal et al., 2021). Additionally, because education, mental health, and social care service provision were rapidly withdrawn (National Autistic Society, 2020), many children with special educational needs and disabilities (SEND) and their families were left without access to their usual support (Coughlan, 2020; O'Connor et al., 2020; Pearcey et al., 2020; Asbury et al., 2021; Family Fund, 2021).

Research based on parental reports has suggested that many children with SEND experienced a decline in their mental health and wellbeing during the pandemic (Alghrani and Byrne, 2020; Disabled Children's Partnership, 2020; Asbury et al., 2021; Council for Disabled Children, 2021; Family Fund, 2021; National Autistic Society, 2020). According to the findings from the Co-SPACE study, as the first lockdown progressed over a 1-month period, children and adolescents with special educational needs (SEN) and neurodevelopmental disorders (ND) had markedly increased emotional difficulties, conduct problems, and hyperactivity/inattention compared to those without SEN/ND (CO-SPACE, 2021; Waite et al., 2021). Moreover, the COVID-19 pandemic has impacted the mental health of families with children with SEND disproportionally. Increases in mental health difficulties could be due to the already higher prevalence of mental health conditions in children with SEND (Simonoff et al., 2008; Neil et al., 2016; Cai et al., 2018; Dehghan et al., 2020; Predescu et al., 2020) and their parents (Asbury et al., 2021). However, another body of growing research suggests that not all families and children with SEND experienced the effects of the pandemic in the same way. Research by the Council for Disabled Children (2021) in England found that restrictions helped some children and young people stay mentally healthy as they enjoyed homeschooling and a slower pace of life. Likewise, the Co-SPACE study demonstrated that children and adolescents with SEN/ND scored lower on conduct problems, hyperactivity/inattention, and emotional symptoms compared to children without SEN/ND who had increased scores across these symptoms during the lockdown (Waite et al., 2021). This was an intriguing finding as it suggested that children with and without SEND have been affected differently by the pandemic; thus, generalizations about the impact of COVID-19 on their wellbeing should be avoided. Further research is required to fully understand the effects of the pandemic on the socioemotional wellbeing of children with SEND.
It has been widely agreed that, generally, the pandemic disrupted the routine of children with SEND including healthy daily habits such as a balanced diet and screen use, and adequate physical exercise and sleep (Geraghty and Lyons, 2021). It has been suggested that these disruptions had had a negative impact on the wellbeing of children with SEND, because they thrive on predictable routines and consistent schedules (Narzisi, 2020; Toseeb et al., 2020). For instance, a study of a small sample of Spanish children with SEND $(n=38)$ aged between 2 and 12 years old found that most children were overusing technology and screens (81.5\%), engaging in little physical exercise (57.9\%), and were eating more $(86.9 \%)$ than usual during the lockdown (Berasategi Sancho et al., 2021). Another study of a sample of Canadian children (mean age: 11.7) found that while children with an autistic spectrum disorder (ASD) used screens as much as children in a community sample during the lockdown, there was a significantly steeper increase in change in screen use time with age for the community sample compared to the ASD sample (Cardy et al., 2021). These mixed findings highlight the need for more research to help understand the impact of the lockdown on the daily habits of children with SEND and in relation to children with no SEND.

In addition to the changes in socioemotional wellbeing and daily habits of children, the lockdown interfered with family life. Families who are raising children with SEND face more stressors than those with children without SEND (McStay et al., 2014; McConnell and Savage, 2015). Such stressors can, in turn, influence the quality of family relationships, making patient and empathic parenting challenging at times (Osborne et al., 2008). Families in several European countries (Italy, Spain, and Belgium; Orgilés et al., 2020; Stassart et al., 2021) and the United Kingdom (Morgül et al., 2020) reported difficulties with family co-existence during the home confinement. In the United Kingdom, families who found co-existence difficult were more likely to report that their children's behavior and emotional state had changed for the worse since the lockdown had started (Morgül et al., 2020). To the best of our knowledge, no study has investigated how families with SEND children coped with family co-existence during the lockdown compared to children without SEND.

The lockdown might have affected children with SEND and their families disproportionately compared to children with no SEND with negative implications for their mental health and wellbeing (Toseeb et al., 2020; Asbury et al., 2021). Despite these negative effects, research is primarily focused on the general child population mostly including neurotypical children (Su et al., 2021). Additionally, emerging research suggests that children with SEND have been impacted differentially in terms of their social and emotional outcomes and daily routines, with some children having experienced poorer wellbeing and adopted poorer habits while for others old habits and wellbeing did not change significantly. Furthermore, the studies vary significantly in terms of sample size, measurement, conceptualization of daily habits, and cultural context, making the interpretation of findings challenging. Finally, more research on how caregivers of children with SEND experienced the confinement and its consequences is required. Therefore, the aim of this study was to examine changes before and during the lockdown in a range of social and 
emotional wellbeing outcomes and in daily habits, and family co-existence difficulty in children with SEN and in relation with children with no SEN in a large sample of children living in the United Kingdom during the first national lockdown.

\section{MATERIALS AND METHODS}

\section{Participants and Procedures}

Caregivers living in the United Kingdom were invited to complete an electronic survey on child and family wellbeing between July and August 2020. The survey was distributed via social networks (e.g., Facebook, Instagram), e-mail, and messaging groups (e.g., WhatsApp). The caregivers were asked to provide sociodemographic information and complete a set of questionnaires about their own mental health and wellbeing, parenting stress, response to COVID-19 lockdown, and about their perception of the impact of the lockdown on their child's psychological wellbeing and daily habits, and of the child's mental health and wellbeing. Children did not participate in the survey. Survey development details have been described in Morgül et al. (2020). The study was approved by the University of Roehampton Research Ethics Committee (PSYC 20/367). The total number of participants were 995 caregivers between 18 and 61 years old $\left(M_{\text {age }}=39.16\right.$ years, $\left.S D=5.62\right)$. Nearly one in six caregivers reported that their children received support for special educational needs $(\mathrm{SEN})\left(n_{\text {SEN }}=169,17.0 \%\right.$; $\left.n_{n o n-S E N}=826,83.0 \%\right)$. The percentage of all pupils in England with SEN support in 2020/21 was $12.2 \%$ (Office for National Statistics, 2021). Therefore, the sample had a higher proportion of children receiving SEN support than the school population in England. Participant characteristics by SEN support are presented in Table 1. Caregivers were mostly of White ethnic background $\left(94.1 \%_{S E N}, 91.4 \%_{\text {non-SEN }}\right)$. Across both samples most caregivers were married $\left(n_{S E N}=105,62.1 \% ; n_{n o n-S E N}=633,76.6 \%\right)$, in employment $\left(n_{\text {SEN }}=105,78.9 \% ; n_{n o n-S E N}=619,85.4 \%\right)$ and had at least a university degree $\left(n_{S E N}=103,63.2 \%\right.$; $\left.n_{n o n-S E N}=657,80.2 \%\right)$. Children were $\left(n_{\text {boys }}-\right.$ SEN $=106,63.1 \%$; $\left.n_{\text {boys-non-_SEN }}=440,53.5 \%\right)$ between 5 and 12 years old $\left(M_{\text {age_SEN }}=8.28\right.$ years; $S D=2.1 ; M_{\text {age_non-SEN }}=7.32$ years, $S D=2.0)$.

\section{Sociodemographic Information and Family Co-existence During the COVID-19 Lockdown}

The first part of the survey included children's and families' sociodemographic characteristics (e.g., participant age, marital status, education level, employment status, ethnicity, and child age, gender, school type, receipt of SEN support. Additionally, caregivers were asked to rate how hard they thought it was for their family to co-exist during the lockdown on a five-point rating scale $(1=$ very easy $-5=$ very difficult $)$.

\section{Child and Caregiver Mental Health and Wellbeing Strengths and Difficulties Questionnaire}

Caregivers completed the parent-reported version of the 25-item Strengths and Difficulties Questionnaire (SDQ) (Goodman, 2001) designed for children between 4 and 17 years old. The SDQ is a psychometrically strong parent-reported questionnaire used internationally to screen for poor mental health and wellbeing in children (Stone et al., 2010). Caregivers are asked to indicate whether the child exhibits a range of emotional and behavioral difficulties on a three-point scale $(0=$ not true -2 = certainly true $)$. The items can be divided between five subscales of five items each (emotional symptoms, conduct problems, hyperactivity, peer problems, and pro-social behavior). Example items include "Considerate of other people's feelings," "Restless, overactive, cannot stay still for long," "Often has temper tantrums or hot tempers." A total difficulty score (range: 0-40) was generated by adding all the subscales, except for the pro-social behavior. Internal reliability of the total SDQ score was good (Cronbach's $\alpha=0.87$ ).

\section{Kessler Psychological Distress Scale (K6)}

The K6 (Kessler et al., 2002) was used to examine caregivers' psychological wellbeing. The K6 assesses the frequency of psychological distress over a period of 30 days prior to administration. It includes six items rated on a 5-point scale $(1=$ all of the time $-5=$ none of the time $)$. Example items include "How often did you feel nervous?" and "How often did you feel hopeless?" Positive valence items were reverse coded. A total score of psychological distress (range: 6-30) was generated by adding all the items. Higher scores reflect higher levels of psychological distress (Kessler et al., 2003). The scale demonstrated excellent internal reliability (Cronbach's $\alpha=0.90$ ).

\section{Parental Stress Scale}

The 18-item self-administered Parental Stress Scale (PSS) was used to assess caregivers' feelings about their parenting role (Berry and Jones, 1995). It comprises four subscales that examine parenting stressors (6 items), loss of control ( 3 items), satisfaction (3 items), and rewards (6 items) rated on a 5-point scale ( 1 = strongly disagree-5 = strongly agree). Example items include "I enjoy spending time with my children" (rewards), "The major source of stress in my life is my children" (stressors), "I feel overwhelmed by the responsibility of being a parent" (loss of control), and "I am happy in my role as a parent" (satisfaction). Eight items are reverse scored. A total parenting stress score was calculated by adding the subscales (range: 18-90) in each sample. Lower scores indicate lower stress levels of stress. Internal reliability was good (Cronbach's $\alpha=0.88$ ).

\section{Change in Child Social and Emotional Wellbeing Before and During the Lockdown}

Caregivers were asked to indicate how much they thought their children's emotional state and behavior changed during the lockdown by rating 11 emotional and behavioral symptom items on a five-point scale ( $1=$ much less compared to before quarantine; 2 = somewhat less compared to before quarantine; 3 = stayed the same; 4 = somewhat more compared to before quarantine; 5 = much more compared to before quarantine) (Morgül et al., 2020). To examine the proportion of children whose emotional and behavioral symptoms changed significantly, a categorical variable was created based on the child's score (1-3 = no change score; $4-5=$ change score). To examine the child's total emotional and behavioral change we created a total internalizing behavior 
TABLE 1 | Between-group differences by participant characteristics.

\begin{tabular}{|c|c|c|c|c|}
\hline & $\begin{array}{c}\text { SEN } \\
(n=169)\end{array}$ & $\begin{array}{r}\text { Non-SEN } \\
(n=826)\end{array}$ & Test & Effect size ${ }^{g}$ \\
\hline Sociodemographics & $f(\%)$ & $f(\%)$ & $x^{2}$ & Phi $\varphi$ /Cramer's V \\
\hline Ethnicity & $159(94.1)$ & $755(91.4)$ & 1.35 & - \\
\hline Married $^{\mathrm{b}}$ & $105(62.1)$ & $633(76.6)$ & $15.41^{\star \star \star}$ & 0.124 \\
\hline Higher education ${ }^{c}$ & $103(63.2)$ & $657(80.2)$ & $22.53^{\star \star \star}$ & 0.151 \\
\hline Boys & $106(63.1)$ & $440(53.5)$ & $5.23^{*}$ & 0.073 \\
\hline Age & $M(S D)$ & $M(S D)$ & $t$ & Cohen's d \\
\hline Caregiver & $39.06(6.65)$ & $39.19(5.39)$ & 0.23 & - \\
\hline Child & $8.28(2.11)$ & $7.32(2.00)$ & $-5.66^{\star \star \star}$ & 0.468 \\
\hline \multicolumn{5}{|l|}{ Mental health and wellbeing } \\
\hline Parental mental health (K6) & $7.92(5.13)$ & $6.61(5.2)$ & $-3.01^{\star \star}$ & 0.254 \\
\hline Internalizing behavior change & $17.75(4.71)$ & $17.33(3.80)$ & -1.07 & - \\
\hline Externalizing behavior change & $21.98(5.14)$ & $21.11(4.47)$ & $-2.03^{\star}$ & 0.181 \\
\hline Family co-existence difficulty & $3.54(1.14)$ & $3.12(1.09)$ & $-4.50^{\star \star \star}$ & 0.377 \\
\hline \multicolumn{5}{|l|}{ Daily habits of children } \\
\hline \multicolumn{5}{|l|}{ Before lockdown } \\
\hline Screen time $e^{e}$ & $2.85(1.02)$ & $2.53(1.06)$ & $-3.57^{\star \star \star}$ & 0.307 \\
\hline Physical activitye & 3.38 (1.39) & $3.27(1.30)$ & -1.05 & - \\
\hline Sleep duration ${ }^{\dagger}$ & $9.20(2.04)$ & $10.05(1.25)$ & $5.26^{\star \star \star}$ & 0.502 \\
\hline \multicolumn{5}{|l|}{ During lockdown } \\
\hline Screen time & $5.08(1.13)$ & 4.54 (1.33) & $-5.48^{\star \star \star}$ & 0.438 \\
\hline Physical activity & $2.92(1.52)$ & $2.74(1.34)$ & -1.44 & - \\
\hline
\end{tabular}

${ }^{a}$ Mother vs. father/caregiver/step-parent.

${ }^{b}$ Married vs. widowed/divorced/separated/never married.

cHigher education/postgraduate vs. non-higher education (up to high school at 16 years and college education).

${ }^{d}$ In employment vs. not in employment/lost job due to COVID-19.

${ }^{e}$ Ranged between 1 and 6: 1-less than $30 \mathrm{~min}, 2-30$ to $60 \mathrm{~min}$, 3-60 to $90 \mathrm{~min}, 4-90$ to $120 \mathrm{~min}, 5-120$ to $180 \mathrm{~min}, 6-\mathrm{more}$ than $180 \mathrm{~min}$.

${ }^{f}$ Duration in hours.

${ }^{g}$ Effect size $=$ Phi $\varphi$ for categorical variables, Cramer's $V$ for multi-categorical variables and Cohen's $d$ for continuous variables.

${ }^{* * *} p<0.001,{ }^{* *} p<0.01,{ }^{*} p<0.05$ (2-tailed).

(5 items; range: $5-25$; Cronbach's $\alpha=0.88$ ) and externalizing behavior (6 items; range: 6-30; Cronbach's $\alpha=0.92$ ) change score, respectively, by summing up the responses of the caregivers across the symptom items. Details on score development can be found in Morgül et al. (2021).

\section{Data Analysis}

Statistical analyses were performed using the IBM SPSS 26 (Statistical Package for the Social Sciences). To check for the assumptions of normality, skewness and kurtosis values were calculated for the dimensional variables. None of them presented extreme skewness and kurtosis values falling outside the proposed threshold values of \pm 2 , suggesting a normal distribution for the variables of interest (George and Mallery, 2010). To compare variables between children receiving SEN support and children not receiving we used Chi-squared tests for categorical variables and independent groups $t$-tests for continuous variables. The effect size of the between-group differences was calculated using Cohen's $d$ for continuous variables, and Phi $\varphi$ or Cramer's $V$ for categorical or multicategorical variables, respectively. To compare differences in change in daily habits before and during the lockdown, we used mixed factorial ANOVA with SEN provision (SEN/nonSEN) the between-group factor and time (before/during) the within-group factor. To measure the size of the difference we used the partial eta square. The Bonferroni statistic was used for intergroup and intragroup multiple comparisons. The homogeneity of variance in a few of the daily habit variables was violated because of unequal group sizes. Therefore, we used a more stringent $p$-value level $(p=0.01)$ for these analyses (Tabachnick et al., 2007). Hierarchical multiple regression analyses were used to examine the independent effect of SEN on children's social and emotional wellbeing before and during the lockdown. 


\section{RESULTS}

\section{Between-Group Differences in Participant Characteristics}

Caregivers of children receiving SEN support, compared to those without this support, were more likely to have spent fewer years in education, be non-married/lone, have significantly higher scores on mental health difficulties and parenting stress, and to experience more difficulty in coping with family coexistence during the lockdown (Table 1). Children who received SEN support, compared to those without SEN support, were reported to experience a significantly higher level of mental health difficulties, and more change in daily habits during the lockdown. Children who received SEN support were older and tended to be boys.

\section{Between-Group Differences in Internalizing and Externalizing Behavior Change During the Lockdown}

Regarding internalizing symptoms, children on SEN support were significantly more worried and anxious during than before the lockdown compared to children without SEN support (Table 2). No statistically significant difference in the total internalizing behavior change score was found (Table 1). Regarding externalizing symptoms, children on SEN support were reported to experience significantly more anger, frustration, irritability, and behavioral problems during than before the lockdown compared to children without SEN support (Table 2). According to the total externalizing behavior change score children with SEN were more likely to experience negative change in their behavior during the lockdown than children with no SEN (Table 1).

TABLE 2 | Between-group differences in caregivers' perception of change in children's internalizing and externalizing symptoms before and during the lockdown.

\begin{tabular}{|c|c|c|c|}
\hline & $\begin{array}{c}\text { SEN } \\
(n=169)\end{array}$ & $\begin{array}{c}\text { Non-SEN } \\
(n=826)\end{array}$ & Test \\
\hline Internalizing symptoms & $f(\%)$ & $f(\%)$ & $x^{2}$ \\
\hline My child is worried & $101(59.8)$ & $419(50.7)$ & $4.59^{\star}$ \\
\hline My child is restless & $101(59.8)$ & $428(51.8)$ & 3.56 \\
\hline My child is anxious & $98(58.0)$ & $351(42.5)$ & $13.60^{\star \star \star}$ \\
\hline My child is sad & $79(46.7)$ & $351(42.5)$ & 1.03 \\
\hline My child is uneasy & $82(48.5)$ & $341(41.3)$ & 3.01 \\
\hline \multicolumn{4}{|l|}{ Externalizing symptoms } \\
\hline My child argues with the rest of the family & $101(59.8)$ & $466(56.4)$ & 0.64 \\
\hline My child cries easily & $63(37.3)$ & $314(38.0)$ & 0.03 \\
\hline My child is angry & $102(60.4)$ & $383(46.4)$ & $10.99^{\star \star}$ \\
\hline My child feels frustrated & $118(69.8)$ & $496(60.0)$ & $5.67^{\star}$ \\
\hline My child is irritable & $112(66.3)$ & $457(55.3)$ & $6.87^{\star *}$ \\
\hline My child has behavioral problems & $78(46.2)$ & $184(22.3)$ & $41.24^{\star \star \star}$ \\
\hline
\end{tabular}

${ }^{* * *} p<0.001,{ }^{* *} p<0.01,{ }^{*} p<0.05$ (2-tailed).

\section{Between-Group Differences in Co-existence Difficulty During the Lockdown}

Caregivers with children with SEN were significantly more likely to report difficulty with co-existence than caregivers with children without SEN (Table 1). The proportion of caregivers of children on SEN support who reported that "co-existence was very difficult" was more than two times higher $(24.9 \%)$ than the proportion of caregivers with children on no-SEN support $(10.2 \%)$. On the contrary, $7.7 \%$ of the caregivers with children on SEN support reported that "co-existence was easy" compared to $18 \%$ of caregivers with children without SEN support.

\section{Between-Group Differences in Daily Routines Before and During the Lockdown}

As shown in Table 1, both before and during the lockdown, children on SEN support tended to spend more time using screens (i.e., iPads, TVs, mobiles, or computers), and slept fewer hours compared to children without SEN support. Mixed factorial ANOVA revealed significant SEN group and time effects on screen time and sleep duration. Specifically, children on SEN support were more likely to spend their time using screens $[F(1$, $\left.993)=24.88, p<0.001, \eta_{p}{ }^{2}=0.024\right]$ and sleep fewer hours $\left[F(1,993)=54.29, p<0.001, \eta_{p}^{2}=0.052\right]$. The group effect was not statistically significant for physical activity $[F(1,993)=2.78$, $\left.p=0.096, \eta_{p}^{2}=0.003\right]$.

Moreover, children across the whole sample were significantly more likely to spend their time using screens $[F(1,993)=1,735$, $\left.p<0.001, \eta_{p}{ }^{2}=0.636\right]$, sleep fewer hours $[F(1,993)=45.10$, $\left.p<0.001, \eta_{p}{ }^{2}=0.043\right]$ and be less physically active $[F(1$, $\left.993)=50.11, p<0.001, \eta_{p}^{2}=0.048\right]$ during the lockdown compared to before. No statistically significant interaction effect between time (before/during) and group (SEN/non-SEN) was found. Differences in daily habits across both groups at different time points are presented in Figures 1-3.

\section{Association of Special Educational Needs With Change in Externalizing Behavior Before and During the Lockdown and Family Co-existence Difficulty}

Two hierarchical regression analyses were conducted to examine further the association of SEN with the total externalizing behavior change score before and during the lockdown (Table 3), and family co-existence difficulty (Table 4). The variables that significantly differentiated between children with and without SEN support were included in the analysis to control for their effects. In the first regression, sociodemographic variables (Step 1) explained a very small proportion of the variance $(1.3 \%)$ in children's externalizing behavior change score. Higher parenting stress and child mental health difficulties significantly contributed to externalizing behavior change (Step 2). The model explained $23.0 \%$ of the variance. In the third step, more family co-existence difficulty predicted more negative change 


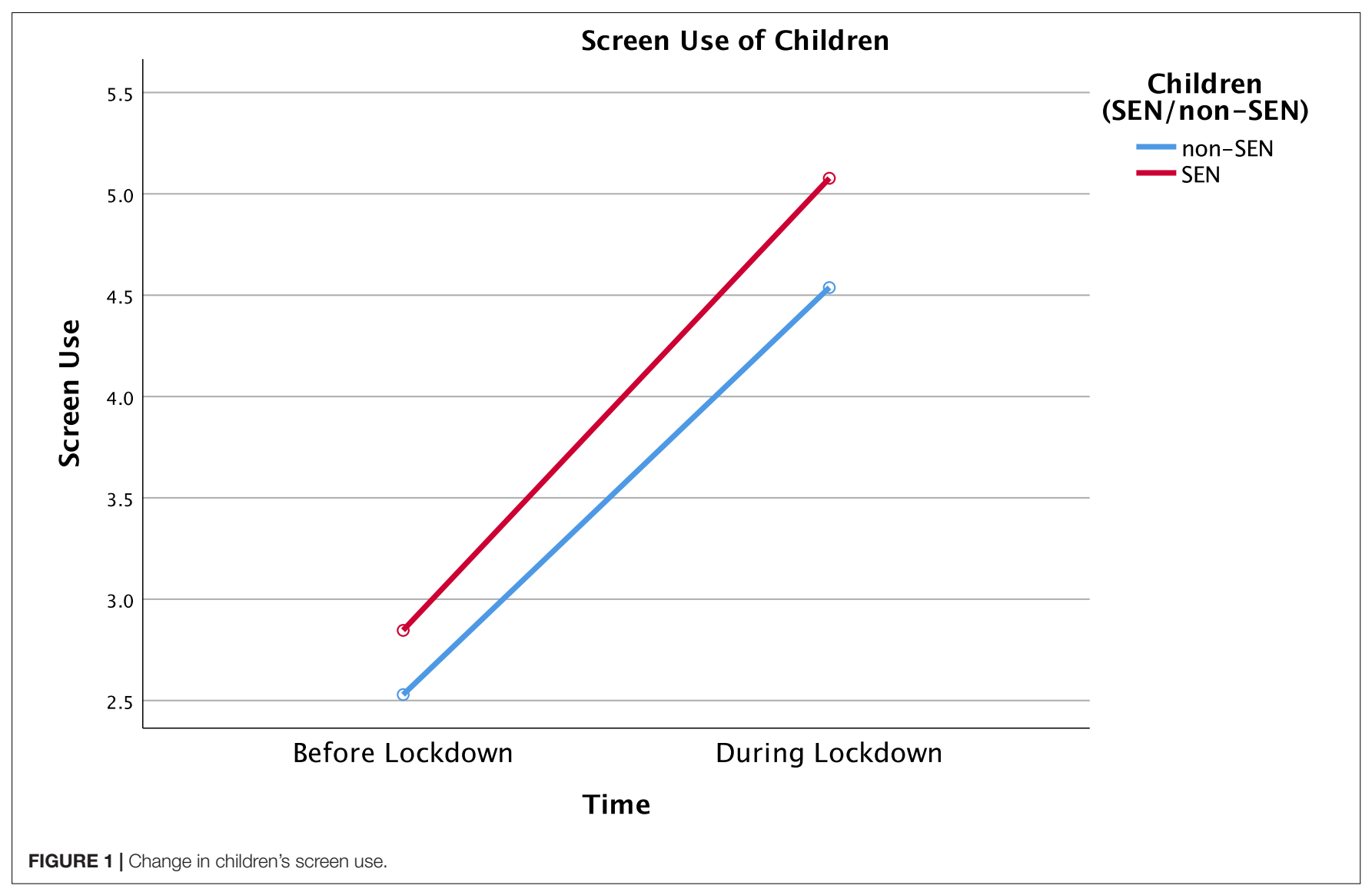

in externalizing behavior. The model explained $29.2 \%$ of the variance. In the fourth step, SEN made a significant but small contribution (1.1\%) to the model which explained $30.3 \%$ of the variance, after controlling for the effects of sociodemographic characteristics, child and caregiver mental health, and family coexistence difficulty. Additionally, the direction of its association with change in externalizing behavior changed to negative suggesting a net or cross-over suppression effect.

The second regression showed that participant sociodemographic characteristics (Step 1) did not contribute significantly to co-existence difficulty. Child and caregiver mental health made a significant contribution to the model (Step 2 ) which explained $26.3 \%$ of the variance in co-existing difficulty. SEN did not contribute significantly to the final model (Step 3) after controlling for sociodemographic factors and family wellbeing. The final model explained $26.3 \%$ of the variance.

\section{Post hoc Analyses of Suppression Effect}

A net or cross-over suppression refers to cases in which two independent variables and a dependent variable correlate positively with each other, but the inclusion of the two independent variables in the regression equation increases the beta of the most influential variable and changes the beta sign of the weakest variable; that is, a positive zero-correlation becomes a negative beta (Cohen and Cohen, 1975; MacKinnon et al., 2002; Paulhus et al., 2004; Watson et al., 2013; Salgado et al., 2019).
In the absence of a statistical test to examine suppression effects (Smith et al., 1992), partial correlation analysis has been suggested to help understand the relationship between the variables involved in a suppression effect (Meehl, 1945; Velicer, 1978; Olusegun et al., 2015). Accordingly, we carried out bivariate, followed by partial correlations, to examine the associations between SEN and externalizing behavior change while controlling for the effect of the variables that significantly predicted externalizing behavior in the final model: child mental health (SDQ), parenting stress (PSS), and co-existence difficulty. The analysis showed that when child mental health was statistically controlled, having SEN was negatively associated with externalizing behavior change $(r=-0.13)$ (Table 5).

\section{DISCUSSION}

Analysis of between-group differences in the mean total internalizing behavior change score showed that according to their caregivers' perceptions, the emotional state of children with SEN was not more impacted than the emotional state of children with no SEN. However, an investigation of the distribution of change across internalizing symptoms demonstrated that, despite the lack of difference in total internalizing behavior change score between the groups, the caregivers of children with SEN were more likely to report that their child was more worried and anxious during the lockdown. Analysis of 


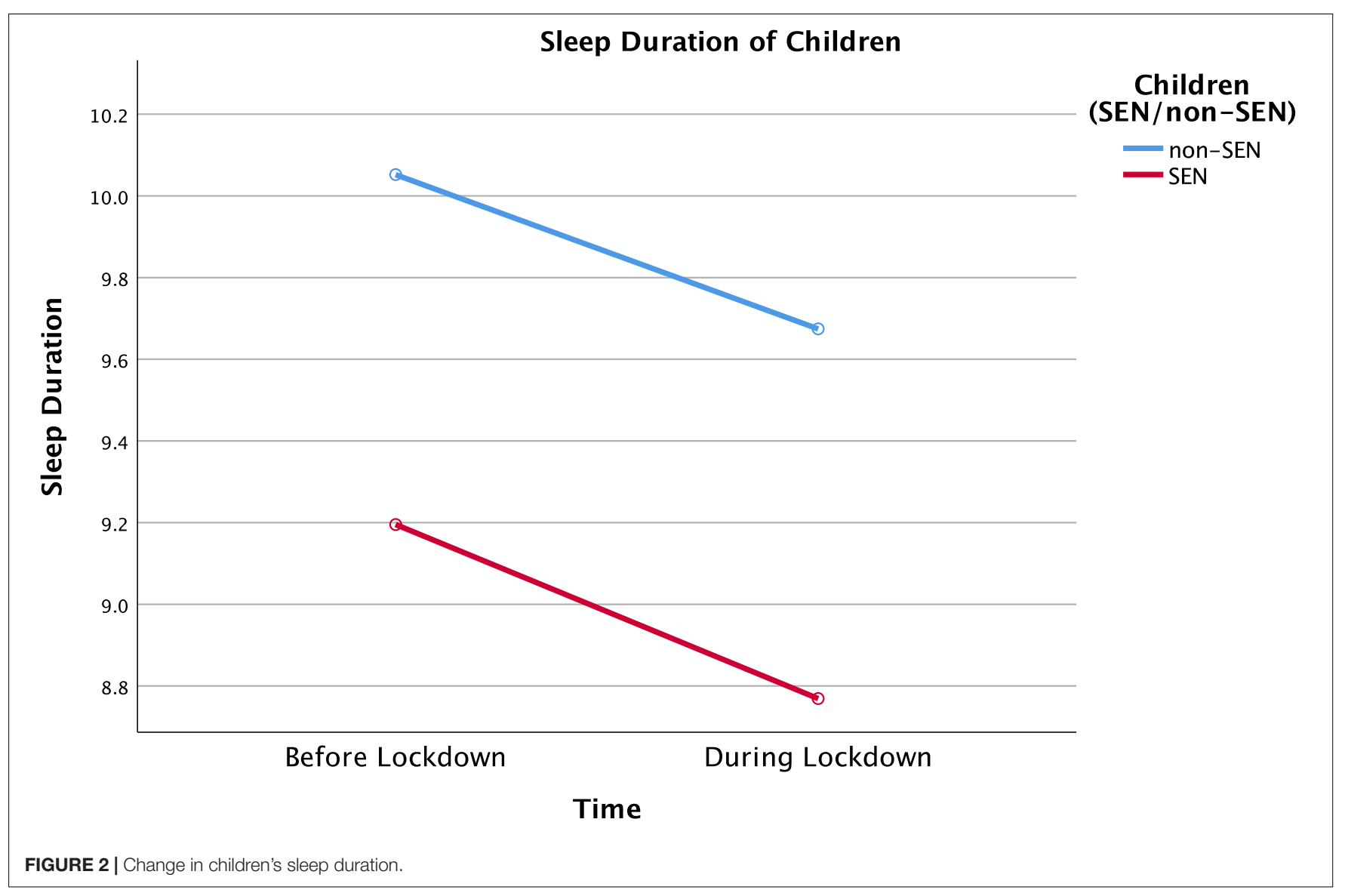

between-group differences in the total externalizing behavior change score showed that the behavior of children with SEN deteriorated significantly more than the behavior of children with no SEN during the lockdown. The caregivers of children with SEN children reported higher levels of anger, frustration, irritability, and behavioral problems. Further analysis showed that the positive association between SEN and negative change in children's externalizing behavior was spurious; once the child's mental health difficulties (SDQ) were held constant, the association became negative. Altogether, our study showed that caregivers with children with SEN were significantly more concerned about the deterioration of their child's behavior compared to those with children with no SEN. While difficulties were found across a range of internalizing and externalizing symptoms, their behavior was more likely to be affected than their emotional state. Our findings agree with the studies that found that children with SEN were more likely to have elevated rates of emotional and behavior difficulties during the lockdown (Nonweiler et al., 2020; Tso et al., 2020; Asbury et al., 2021; Berasategi Sancho et al., 2021; CO-SPACE, 2021; Family Fund, 2021). Because pre-pandemic prevalence of mental health difficulties in England is higher among children with SEN (McGinnity et al., 2005; Office for National Statistics, 2021) it is unclear whether the increased behavioral problems of children with SEN in our sample was the result of the lockdown or pre-pandemic poor mental health. However, the post hoc analysis showed that the children with SEN who had fewer behavioral difficulties during the lockdown were the ones with stronger mental health. This finding suggests that poor mental health was an important risk factor of poor socioemotional wellbeing in children with SEN during the lockdown. Additionally, it emphasizes the protective role of mental health and wellbeing in children with SEN (Panchal et al., 2021; Raw et al., 2021; Waite et al., 2021) and the need to support the mental health and wellbeing of children and young people with SEN (Skrzypiec et al., 2016). As well as child mental health, emerging research points out to additional individual factors that may modulate the impact of the COVID-19 lockdown on children's outcomes. For instance, recent research has placed emphasis on the effects of personality traits, coping methods and alexithymia as they were found to have a differential impact on COVID-19 related emotional responses such as anxiety and stress (Osimo et al., 2021) and emotional eating (Cecchetto et al., 2021). Additionally, irritability has been suggested to interfere with the emotional state of non-neurotypical children during the lockdown (Türkoğlu et al., 2021; Uçar et al., 2021). Further research to understand how these individual factors were implicated in the emotional and behavioral wellbeing of children with SEN during the lockdown is warranted.

Another finding was that while, generally, children with SEN were perceived to have worse behavior than children without SEN, the children with SEN but without mental health difficulties 


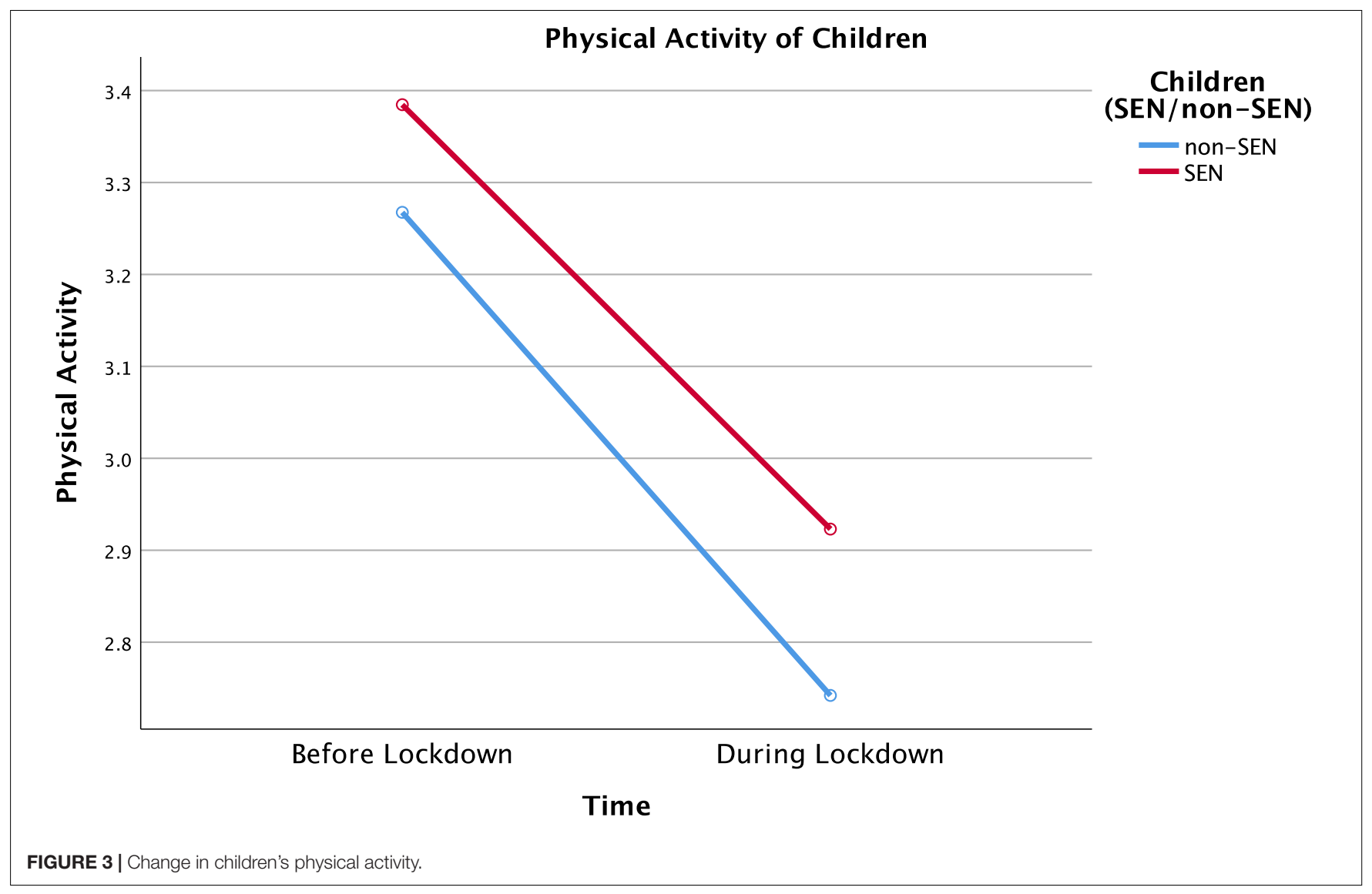

TABLE 3 | Hierarchical regression summary predicting children's externalizing behavior change before and during the lockdown in the United Kingdom.

\begin{tabular}{|c|c|c|c|c|c|c|c|c|}
\hline & \multicolumn{2}{|c|}{ Step 1} & \multicolumn{2}{|c|}{ Step 2} & \multicolumn{2}{|c|}{ Step 3} & \multicolumn{2}{|c|}{ Step 4} \\
\hline Education level & $-0.94(0.36)$ & $-0.09^{\star \star}$ & $-0.10(0.33)$ & -0.01 & $-0.19(0.31)$ & -0.02 & $-0.27(0.31)$ & -0.03 \\
\hline Marital status & $-0.65(0.34)$ & -0.06 & $0.05(0.31)$ & 0.00 & $0.04(0.29)$ & 0.00 & $-0.01(0.29)$ & 0.00 \\
\hline Child age & $-0.02(0.07)$ & -0.01 & $-0.09(0.06)$ & -0.04 & $-0.06(0.06)$ & -0.03 & $-0.03(0.06)$ & -0.01 \\
\hline Child gender & $-0.15(0.29)$ & -0.02 & $0.08(0.26)$ & 0.01 & $0.16(0.25)$ & 0.02 & $0.12(0.25)$ & 0.01 \\
\hline Parenting stress (PSS) & & & $0.08(0.02)$ & $0.17^{\star \star \star}$ & $0.04(0.02)$ & $0.08^{\star}$ & $0.04(0.02)$ & $0.08^{\star}$ \\
\hline Co-existence difficulty & & & & & $1.20(0.13)$ & $0.29^{\star \star \star}$ & $1.21(0.13)$ & $0.29^{\star \star \star}$ \\
\hline Special educational needs (SEN) & & & & & & & $-1.44(0.36)$ & $-0.12^{\star \star \star}$ \\
\hline$R^{2}$ & $0.013^{*}$ & & $0.230^{\star \star *}$ & & $0.292^{\star \star \star}$ & & $0.303^{\star \star \star}$ & \\
\hline$\Delta R^{2}$ & 0.013 & & 0.216 & & 0.062 & & 0.011 & \\
\hline
\end{tabular}

${ }^{* * *} p<0.001,{ }^{* *} p<0.01,{ }^{*} p<0.05$ (2-tailed).

behaved better during the lockdown. This finding is compatible with the latest longitudinal findings from the Co-SPACE study which found that particularly younger boys with SEND had less severe hyperactivity and inattention symptoms between June and July 2020 (Raw et al., 2021). Our finding is also consistent with earlier results from the Co-Space study which revealed reductions in externalizing problems (conduct and hyperactivity/inattention) among children and adolescents with
SEND during the early lockdown between March to May 2020 (Waite et al., 2021) as well as other studies which found that children and young people with SEND reported that their mental health improved during the lockdown (Mind, 2020; Mansfield et al., 2021). Hence, it appears that, at least for some children, the lockdown may have eased some challenging areas of life, while children with mental health difficulties were significantly impacted regardless of whether they had SEN. It is important 
TABLE 4 | Hierarchical regression summary predicting co-existence difficulty during the lockdown in the United Kingdom.

\begin{tabular}{|c|c|c|c|c|c|c|}
\hline & \multicolumn{2}{|c|}{ Step 1} & \multicolumn{2}{|c|}{ Step 2} & \multicolumn{2}{|c|}{ Step 3} \\
\hline & $B$ (SE) & $b$ & $B(S E)$ & $b$ & $B(S E)$ & $b$ \\
\hline Marital status & $-0.16(0.08)$ & -0.06 & $0.01(0.07)$ & 0.00 & $0.01(0.07)$ & 0.00 \\
\hline Child age & $-0.01(0.02)$ & -0.02 & $-0.03(0.02)$ & -0.05 & $-0.03(0.02)$ & $-0.06^{\star}$ \\
\hline Child gender & $-0.09(0.07)$ & -0.04 & $-0.06(0.06)$ & -0.03 & $-0.06(0.06)$ & -0.03 \\
\hline Parenting stress (PSS) & & & $0.03(0.00)$ & $0.31^{* \star *}$ & $0.03(0.00)$ & $0.31^{\star \star \star}$ \\
\hline Special educational needs (SEN) & & & & & $0.06(0.09)$ & 0.02 \\
\hline$R^{2}$ & 0.007 & & $0.263^{\star \star \star}$ & & 0.263 & \\
\hline$\Delta R^{2}$ & 0.007 & & 0.256 & & 0.000 & \\
\hline$\Delta F$ & 1.71 & & 112.23 & & 0.39 & \\
\hline
\end{tabular}

${ }^{* * *} p<0.001,{ }^{* *} p<0.01,{ }^{*} p<0.05$ (2-tailed).

TABLE 5 | Bivariate and partial correlations.

\begin{tabular}{|c|c|c|c|}
\hline & Control variables & Significant study variables in regression & Externalizing behavior change \\
\hline & & Special educational needs (SEN) & $0.07^{\star}$ \\
\hline & & Parenting Stress (PSS) & $0.35^{\star \star}$ \\
\hline & & Co-existence difficulty & $0.44^{\star *}$ \\
\hline \multirow[t]{3}{*}{ Partial correlations } & Child mental health (SDQ) & Externalizing behavior change & - \\
\hline & & Parenting Stress (PSS) & $0.16^{\star \star}$ \\
\hline & & Co-existence difficulty & $0.32^{\star \star}$ \\
\hline
\end{tabular}

${ }^{* *} p<0.01,{ }^{*} p<0.05$ (2-tailed).

Sign switch in SEN variable is highlighted in bold.

to identify why some children experienced fewer behavior difficulties while not at school; potentially schools cannot meet the needs of all children (Castro-Kemp and Mahmud, 2021).

The results showed that there was a significant increase in screen time and decrease in sleep time for both groups of children. This finding is in line with other studies of technology use during the pandemic in the general child population across the world (Moore et al., 2020; Pietrobelli et al., 2020; Xiang et al., 2020). While the change in daily screen time increased equally for both groups over a month of lockdown, children with SEN were using screens more often than children with no SEN both before and during the lockdown. The American Academy of Pediatrics Council on Communications and Media (2016) recommends no more than 2 hours of screen time per day for school-aged children (2016). However, children with SEN including children with anxiety, ASD, learning disabilities, or attention-deficit/hyperactivity disorder tend to use devices as a coping mechanism (Close and Fogler, 2020). Therefore, determining screen time limits can be especially stressful for families of children with SEN especially during the lockdown. The COVID-19 pandemic has also imposed digital platforms as the only means for people to maintain social and emotional connection (Kanekar and Sharma, 2020). Research on screen use reflects both positive and negative consequences of screen time on child mental health. Research by the UK Council for Disabled Children (2021) found that some children with SEN liked not having to go out and interact with others face-to-face. Instead, they learnt how to connect with their friends over online gaming because they found this way of communication easier. Though digital devices kept many of these children socially and emotionally connected, excessive screen time has also negative mental health impacts including attention-deficit symptoms, depression, anxiety, and technology addiction (Amin et al., 2020; Dienlin and Johannes, 2020; King et al., 2020; Lanca and Saw, 2020; Oswald et al., 2020; Xiang et al., 2020; Hudimova, 2021; Wong et al., 2021). Because there are mixed consequences of prolonged screen use on children with SEN, further research is necessary to understand how to balance the positive effects of digital social connectedness and negative effects of excessive use in children with SEN.

Families supporting their child's complex and special needs at home had little or no other support (i.e., wider family support, individual educational therapy support, institutional, and mental support) available to them at the time of the lockdown (Su et al., 2021). Moreover, other lockdown related factors such as lack of coping mechanisms, isolation from social support networks, disruption in routines, challenging family circumstances, and financial hardship might have caused additional difficulties for 
these families (Merello, 2021; Su et al., 2021). In this context, the experience of the confinement and its consequences might have been more challenging for children with SEN and their families. A growing body of research has shown that caregivers with children with SEN/D found caring for their children during the lockdown difficult (Castro-Kemp and Mahmud, 2021; Kallitsoglou and Topalli, 2021). As expected, we also found that caregivers with children with SEN reported significantly high rates of family co-existence difficulty. Additionally, they were more likely to report difficulty than caregivers with children without SEN. Notably, however, we found that SEN did not significantly predict co-existence difficulty when child and caregiver characteristics were statistically controlled. Specifically, the findings demonstrated that families with SEN children found the confinement more challenging because of associated family adversity (i.e., poor parental mental health and associated stress around parenting), and the child's poor mental health and not the child's SEN per se. Our findings point out to the child's family ecology as a potential explanatory factor of the difficulties that the families with children with SEN experienced during the lockdown. Moreover, they highlight the significance of caregiver and child mental health for a harmonious family life (Prime et al., 2020).

The findings should be interpreted in relation to the study's methodological limitations. The cross-sectional design did not allow to examine the long-term impact of the lockdown on children's internalizing and externalizing behavior and daily habits. Additionally, changes in children's symptoms were based only on perceived caregiver report. Majority of participants were white female university graduates. Therefore, generalization of the findings should be approached with caution. Furthermore, since we did not have pre-pandemic data, it is difficult to understand if the behavioral symptoms change was due to the lockdown or pre-existing levels of mental health difficulties in children with SEN. Replication studies should include a longitudinal design, multi-informant assessment methods of children's emotional and behavioral difficulties, and examination of passive vs. interactive screen time. These limitations notwithstanding, our findings have implications for supporting families with SEN. Our study showed that poor mental health was an important risk factor of the wellbeing of children with SEN during the pandemic. Mental health lay the foundation from which children and young people can start exploring the learning opportunities available to them (Weisbrot and Ryst,

\section{REFERENCES}

Alghrani, A., and Byrne, S. (2020). The Impact of COVID-19 on Education and Children's Services. Liverpool: University of Liverpool.

American Academy of Pediatrics Council on Communications and Media (2016). Media and young minds. Pediatrics 138:e20162591. doi: 10.1542/peds.20162591

Amin, K. P., Griffiths, M. D., and Dsouza, D. D. (2020). Online gaming during the COVID-19 pandemic in India: strategies for work-life balance. Int. J. Ment. Health Addict. [Epub ahead of print]. doi: 10.1007/s11469-020-00358-1

Asbury, K., Fox, L., Deniz, E., Code, A., and Toseeb, U. (2021). How is COVID19 affecting the mental health of children with special educational needs and
2020). Therefore, the aims of education post-pandemic should be re-examined and consider the systematic implementation of school-wide and selective evidence-based intervention programs to support the outcomes of children with SEN. Furthermore, the caregivers with children with SEN who experienced more difficulty with the confinement were those who experienced more adversity such as poor mental health. Consistent with research on family risk and resilience and the benefits of positive parenting for children's emotional and behavioral outcomes before and during the lockdown (Prime et al., 2020; Raw et al., 2021), our research calls for more concerted action to support the caregivers of children with SEN.

\section{DATA AVAILABILITY STATEMENT}

The raw data supporting the conclusions of this article will be made available by the authors, without undue reservation.

\section{ETHICS STATEMENT}

The studies involving human participants were reviewed and approved by the University of Roehampton Research Ethics Committee (PSYC 20/367). The patients/participants provided their written informed consent to participate in this study.

\section{AUTHOR CONTRIBUTIONS}

EM: data collection, data analysis and interpretation, methodology, software, writing the original draft, and revision. AK: conceptualization, methodology, writing, revision, editing, data interpretation, and supervision. CE: supervision and editing. SC-K: comments to final version. All authors contributed to the article and approved the submitted version.

\section{ACKNOWLEDGMENTS}

We thank the families who participated in our survey for sharing their views and personal experiences during challenging times of COVID-19 lockdown. We are grateful to them for their openness and honesty about their mental health and that of their children.

disabilities and their families? J. Autism Dev. Disord. 51, 1772-1780. doi: 10. 1007/s10803-020-04577-2

Berasategi Sancho, N., Idoiaga Mondragon, N., Dosil Santamaria, M., and Picaza Gorrotxategi, M. (2021). The well-being of children with special needs during the COVID-19 lockdown: academic, emotional, social and physical aspects. Eur. J. Spec. Needs Educ. [Epub ahead of print]. doi: 10.1080/08856257.2021. 1949093

Berry, J. O., and Jones, W. H. (1995). The parental stress scale: initial psychometric evidence. J. Soc. Pers. Relat. 12, 463-472. doi: 10.1177/0265407595123009

Cai, R. Y., Richdale, A. L., Uljarević, M., Dissanayake, C., and Samson, A. C. (2018). Emotion regulation in autism spectrum disorder: where we are and where we need to go. Autism Res. 11, 962-978. doi: 10.1002/aur.1968 
Cardy, R. E., Dupuis, A., Anagnostou, E., Ziolkowski, J., Biddiss, E. A., Monga, S., et al. (2021). Characterizing changes in screen time during the COVID-19 pandemic school closures in Canada and its perceived impact on children with autism spectrum disorder. Front. Psychiatry 12:702774. doi: 10.3389/fpsyt.2021. 702774

Castro-Kemp, S., and Mahmud, A. (2021). School closures and returning to school: views of parents of children with disabilities in England during the Covid-19 pandemic. Front. Educ. 6:149. doi: 10.3389/feduc.2021.666574

Cecchetto, C., Aiello, M., Gentili, C., Ionta, S., and Osimo, S. A. (2021). Increased emotional eating during COVID-19 associated with lockdown, psychological and social distress. Appetite 160:105122. doi: 10.1016/j.appet.2021.105122

Close, M., and Fogler, J. (2020). Zooming in On Screen Time for Children with Special Education Needs. Boston: Boston Children's Hospital News and World Report.

Cohen, J., and Cohen, P. (1975). Applied Multiple Regression/Correlation Analysis for the Behavioural Sciences. Mahwah, NJ: Lawrence Erlbaum.

CO-SPACE (2021). Report 08: Changes in Children's and Young People's Mental Health Symptoms: March 2020 to January 2021. Available online at: https://cospaceoxford.org/wp-content/uploads/2021/02/Co-SPACE-report08_06-09-21.pdf (accessed December 12, 2021).

Coughlan, T. (2020). Simon Bridges Says the Lockdown Should be Lifted Next Week. Available online at: https:/www.stuff.co.nz/national/health/coronavirus/ 121018830/coronavirus-simon-bridges-says- thelockdown-should-be-liftednext-week (accessed December 10, 2021).

Council for Disabled Children (2021). Lessons Learnt from Lockdown: The Highs and Lows of the Pandemic's Impact on Disabled Children and Young People: Children and Young People's Summary. Available online at: https://councilfordisabledchildren.org.uk/sites/default/files/uploads/ attachments/Lessons\%20Learnt\%20From\%20Lockdown_Children\%20and\% 20Young\%20People\%27s\%20Summary.pdf (accessed December 14, 2021).

Creswell, C., Shum, A., Pearcey, S., Skripkauskaite, S., Patalay, P., and Waite, P. (2021). Young people's mental health during the COVID-19 pandemic. Lancet Child. Adolesc. Health 5, 535-537. doi: 10.1016/S2352-4642(21)00177-2

Dehghan, F., Kaboudi, M., Alizadeh, Z., and Heidarisharaf, P. (2020). The relationship between emotional intelligence and mental health with social anxiety in blind and deaf children. Cogent. Psychol. 7:1716465. doi: 10.1080/ 23311908.2020.1716465

Dienlin, T., and Johannes, N. (2020). The impact of digital technology use on adolescent well-being. Dialog. Clin. Neurosci. 22, 135-142. doi: 10.31887/dcns. 2020.22.2/tdienlin

Disabled Children's Partnership (2020). Left In Lockdown - Parent Carers' Experiences of Lockdown. Available online at: https: //disabledchildrenspartnership.org.uk/wp-content/uploads/2020/06/ LeftInLockdown-Parent-carers\%E2\%80\%99-experiences-of-lockdownJune-2020.pdf (accessed December 8, 2021).

Family Fund (2021). The Impact of Coronavirus: A Year in the Life of Families Raising Disabled and Seriously Ill Children and Young People. Available online at: https://www.familyfund.org.uk/Handlers/Download.ashx?IDMF=c7e2f959c183-49e8-bef8-1a7ae8e12e6e (accessed December 16, 2021).

George, D., and Mallery, M. (2010). SPSS for Windows Step by Step: A Simple Guide and Reference, 17.0 Update (10a ed.). Boston: Pearson.

Geraghty, T., and Lyons, F. (2021). Insights into the Impact of COVID-19 on Children and Young People with special educational NEEDS and Disabilities in Northern Ireland - Final Report. National Children's Bureau. Available online at: https://www.ncb.org.uk/sites/default/files/uploads/files/Impact $\% 20 \mathrm{of} \%$ 20COVID- $19 \% 20$ on $\% 20$ children $\% 20$ and $\% 20$ YP\%20with\%20SEND $\% 20$ in $\%$ 20NI\%20-\%20FIINAL.pdf (accessed November 18, 2021).

Goodman, R. (2001). Psychometric properties of the strengths and difficulties questionnaire. J. Am. Acad. of Child Adolesc. Psychiatry 40, 1337-1345.

Holmes, E. A., O'Connor, R. C., Perry, V. H., Tracey, I., Wessely, S., Arseneault, L., et al. (2020). Multidisciplinary research priorities for the COVID-19 pandemic: a call for action for mental health science. Lancet Psychiatry 7, 547-560. doi: 10.1016/S2215-0366(20)30168-1

Hudimova, A. (2021). Adolescents' involvement in social media: before and during COVID-19 pandemic. Int. J. Innov. Technol. Soc. Sci. 1:7370.

Kallitsoglou, A., and Topalli, P. Z. (2021). Coping with homeschooling and caring for children during the UK COVID-19 lockdown: voices of working mothers. Res. Square [Epub ahead of print]. doi: 10.21203/rs.3.rs-333649/v1
Kanekar, A., and Sharma, M. (2020). COVID-19 and mental well-being: guidance on the application of behavioral and positive well-being strategies. Healthcare 8:336. doi: 10.3390/healthcare8030336

Kessler, R. C., Andrews, G., Colpe, L. J., Hiripi, E., Mroczek, D. K., Normand, S. L., et al. (2002). Short screening scales to monitor population prevalences and trends in non-specific psychological distress. Psychol. Med. 32, 959-976. doi: 10.1017/S0033291702006074

Kessler, R. C., Barker, P. R., Colpe, L. J., Epstein, J. F., Gfroerer, J. C., Hiripi, E., et al. (2003). Screening for serious mental illness in the general population. Arch. Gen. Psychiatry 60, 184-189. doi: 10.1001/archpsyc.60.2.184

King, D. L., Delfabbro, P. H., Billieux, J., and Potenza, M. N. (2020). Problematic online gaming and the COVID-19 pandemic. J. Behav. Addict. 9, 184-186. doi: $10.1556 / 2006.2020 .00016$

Lanca, C., and Saw, S. M. (2020). The association between digital screen time and myopia: a systematic review. Ophthalm. Physiol. Opt. 40, 216-229. doi: 10.1111/opo. 12657

MacKinnon, D. P., Lockwood, C. M., Hoffman, J. M., West, S. G., and Sheets, V. (2002). A comparison of methods to test mediation and other intervening variable effects. Psychol. Methods 7:83. doi: 10.1037/1082-989X.7.1.83

Mansfield, K., Jindra, C., Geulayov, G., and Fazel, M. (2021). Self-reported wellbeing and sample characteristics in a survey of 19000 school pupils during the first UK COVID-19 school closures. psyAriXiv [Preprint]. doi: 10.31234/osf. io/gtbfm

McConnell, D., and Savage, A. (2015). Stress and resilience among families caring for children with intellectual disability: expanding the research agenda. Curr. Dev. Disord. Rep. 2, 100-109. doi: 10.1007/s40474-015-0040-z

McGinnity, Á, Meltzer, H., Ford, T., and Goodman, R. (2005). Mental Health of Children and Young People in Great Britain, 2004. Basingstoke: Palgrave Macmillan.

McStay, R. L., Dissanayake, C., Scheeren, A., Koot, H. M., and Begeer, S. (2014). Parenting stress and autism: the role of age, autism severity, quality of life and problem behaviour of children and adolescents with autism. Autism: Int. J. Soc. Res. Methodol. 18, 502-510. doi: 10.1177/1362361313485163

Meehl, P. E. (1945). A simple algebraic development of Horst's suppressor variables. Am. J. Psychol. 58, 550-554. doi: 10.2307/1417770

Merello, Á (2021). Barriers and Facilitators for Children with Special Educational Needs Education During the COVID-19 Pandemic: A Systematic Literature Review in 2020. [dissertation/master's thesis]. Sweden: Jönköping University.

Mind (2020). The Mental Health Emergency: How Has the Coronavirus Pandemic Impacted Our Mental Health?. Available online at: https://www.mind.org. uk/media-a/5929/the-mental-health-emergency_a4_final.pdf (accessed November 15, 2021).

Moore, S. A., Faulkner, G., Rhodes, R. E., Brussoni, M., Chulak-Bozzer, T., Ferguson, L. J., et al. (2020). Impact of the COVID-19 virus outbreak on movement and play behaviors of Canadian children and youth: a national survey. Int. J. Behav. Nutr. Phys. Act. 17, 1-11. doi: 10.1186/s12966-020-00 $987-8$

Morgül, E., Kallitsoglou, A., and Essau, C. A. (2020). Psychological effects of the COVID-19 lockdown on children and families in the UK. Rev. Psicol. Clín. Con Niños Adolesc. 7, 42-48. doi: 10.21134/rpcna.2020.mon.2049

Morgül, E., Kallitsoglou, A., and Essau, C. A. (2021). Predictors of change in children's internalising and externalising behaviour before and during the initial COVID-19 lockdown in the UK and Turkey: a cross-cultural examination. Res. Square [Epub ahead of print]. doi: 10.21203/rs.3.rs$1184183 / \mathrm{v} 2$

Narzisi, A. (2020). Handle the autism spectrum condition during coronavirus (COVID-19) stay at home period: ten tips for helping parents and caregivers of young children. Brain Sci. 10:207. doi: 10.3390/brainsci1004 0207

National Autistic Society (2020). Left Stranded: The Impact of Coronavirus on Autistic People and Their Families in the UK. Available online at: https://s4.chorus-mk.thirdlight.com/file/1573224908/63117952292/width=-1/ height $=-1 /$ format $=-1 /$ fit $=$ scale $/ \mathrm{t}=444295 / \mathrm{e}=$ never $/ \mathrm{k}=\mathrm{da} 5 \mathrm{c} 189 \mathrm{a} / \mathrm{LeftStranded} \%$ 20Report.pdf (accessed October 16, 2021).

Neil, L., Olsson, N. C., and Pellicano, E. (2016). The relationship between intolerance of uncertainty, sensory sensitivities, and anxiety in autistic and typically developing children. J. Autism Dev. Disord. 46, 1962-1973. doi: 10. 1007/s10803-016-2721-9 
Nonweiler, J., Rattray, F., Baulcomb, J., Happé, F., and Absoud, M. (2020). Prevalence and associated factors of emotional and behavioral difficulties during COVID-19 pandemic in children with neurodevelopmental disorders. Children 7:128. doi: 10.3390/children7090128

O'Connor, C., Gallagher, E., Walsh, E., and McMahon, J. (2020). Report 02: COVID-19 Worries, Parent/Carer Stress and Support Needs, by Child Special Educational. Oxford: University of Oxford, Emerging Minds.

Office for National Statistics (2021). Special Educational Needs in England. Oxford: University of Oxford, Emerging Minds.

Olusegun, A. M., Muktar, A., Kabir, K. N., Adamu, I. A., and Abubakar, U. A. (2015). How a variable's partial correlation with other variable (s) can make a good predictor: the suppressor variable case. Int. J. Adv. Stat. Probab. 3:210. doi: 10.14419/ijasp.v3i2.5400

Orgilés, M., Morales, A., Delvecchio, E., Mazzeschi, C., and Espada, J. P. (2020). Immediate psychological effects of the COVID-19 quarantine in youth from Italy and Spain. Front. Psychol. 11:2986. doi: 10.3389/fpsyg.2020.579038

Osborne, L. A., McHugh, L., Saunders, J., and Reed, P. (2008). Parenting stress reduces the effectiveness of early teaching interventions for autistic spectrum disorders. J. Autism Dev. Disord. 38:1092. doi: 10.1007/s10803-007-0497-7

Osimo, S. A., Aiello, M., Gentili, C., Ionta, S., and Cecchetto, C. (2021). The influence of personality, resilience, and alexithymia on mental health during COVID-19 pandemic. Front. Psychol. 12:630751. doi: 10.3389/fpsyg.2021. 630751

Oswald, T. K., Rumbold, A. R., Kedzior, S. G. E., and Moore, V. M. (2020). Psychological impacts of "screen time" and "green time" for children and adolescents: a systematic scoping review. PLoS One 15:e0237725. doi: 10.1371/ journal.pone. 0237725

Panchal, U., Salazar de Pablo, G., Franco, M., Moreno, C., Parellada, M., Arango, C., et al. (2021). The impact of COVID-19 lockdown on child and adolescent mental health: systematic review. Eur. Child Adolesc. Psychiatry [Epub ahead of print]. doi: 10.1007/s00787-021-01856-w

Paulhus, D. L., Robins, R. W., Trzesniewski, K. H., and Tracy, J. L. (2004). Two replicable suppressor situations in personality research. Multiv. Behav. Res. 39, 303-328. doi: 10.1207/s15327906mbr3902_7

Pearcey, S., Shum, A., Waite, P., Patalay, P., and Creswell, C. (2020). The Co-Space Study Report 04: Changes in Children and Young People's Emotional and Behavioural Difficulties Through Lockdown. Available online at: https://emergingminds.org.uk/wp-content/uploads/2020/06/CoSPACEReport-4-June-2020.pdf (accessed June 16, 2020).

Pietrobelli, A., Pecoraro, L., Ferruzzi, A., Heo, M., Faith, M., Zoller, T., et al. (2020). Effects of COVID-19 lockdown on lifestyle behaviors in children with obesity living in Verona, Italy: a longitudinal study. Obesity 28, 1382-1385. doi: 10.1002/oby.22861

Predescu, E., Sipos, R., Costescu, C. A., Ciocan, A., and Rus, D. I. (2020). Executive functions and emotion regulation in attention-deficit/hyperactivity disorder and borderline intellectual disability. J. Clin. Med. 9:986. doi: 10.3390/ jcm9040986

Prime, H., Wade, M., and Browne, D. T. (2020). Risk and resilience in family well-being during the COVID-19 pandemic. Am. Psychol. 75, 631-643. doi: 10.1037/amp0000660

Raw, J., Waite, P., Pearcey, S., Shum, A., Patalay, P., and Creswell, C. (2021). Examining changes in parent-reported child and adolescent mental health throughout the UK's first COVID-19 national lockdown. J. Child. Psychol. Psychiatry 62, 1391-1401. doi: 10.1111/jcpp.13490

Salgado, J. F., Blanco, S., and Moscoso, S. (2019). Subjective well-being and job performance: testing of a suppressor effect. J. Work. Organ. Psychol. 35, 93-102.

Simonoff, E., Pickles, A., Charman, T., Chandler, S., Loucas, T., and Baird, G. (2008). Psychiatric disorders in children with autism spectrum disorders: prevalence, comorbidity, and associated factors in a population-derived sample. J. Am. Acad. Child Adolesc. Psychiatry 47, 921-929. doi: 10.1097/CHI. 0b013e318179964f

Skrzypiec, G., Askell-Williams, H., Slee, P., and Rudzinski, A. (2016). Students with self-identified special educational needs and disabilities (si-SEND): flourishing or languishing! Intl. J. Disabil. Dev. and Educ. 63, 7-26. doi: 10.1080/1034912X. 2015.1111301

Smith, R. L., Ager, J. W. Jr., and Williams, D. L. (1992). Suppressor variables in multiple regression/correlation. Educ. Psychol. Meas. 52, 17-29. doi: 10.1177/ 001316449205200102
Stassart, C., Wagener, A., and Etienne, A. M. (2021). Parents' perceived impact of the societal lockdown of COVID-19 on family well-being and on the emotional and behavioral state of Walloon Belgian children aged 4 to 13 Years: an exploratory study. Psychol. Belg. 61:186. doi: 10.5334/pb.1059

Stone, L. L., Otten, R., Engels, R. C., Vermulst, A. A., and Janssens, J. M. (2010). Psychometric properties of the parent and teacher versions of the strengths and difficulties questionnaire for 4-to 12-year-olds: a review. Clin. Child. Fam. Psychol. Rev. 13, 254-274. doi: 10.1007/s10567-010-0071-2

Su, X., Cai, R. Y., Uljarević, M., Van Herwegen, J., Dukes, D., Yang, Y., et al. (2021). Brief report: a cross-sectional study of anxiety levels and concerns of Chinese families of children with special educational needs and disabilities postfirst-wave of COVID-19. Front. Psychiatry 12:708465. doi: 10.3389/fpsyt.2021. 708465

Tabachnick, B. G., Fidell, L. S., and Ullman, J. B. (2007). Using Multivariate Statistics. Boston, MA: Pearson, 481-498.

Toseeb, U., Asbury, K., Code, A., Fox, L., and Deniz, E. (2020). Supporting families with children with special educational needs and disabilities during COVID-19. PsyArXiu [Prepints]. doi: 10.31234/osf.io/tm69k

Tso, W., Wong, R. S., Tung, K., Rao, N., Fu, K. W., Yam, J., et al. (2020). Vulnerability and resilience in children during the COVID-19 pandemic. Eur. Child. Adolesc. Psychiatry [Epub ahead of print]. doi: 10.1007/s00787-02001680-8

Türkoğlu, S., Uçar, H. N., Çetin, F. H., Güler, H. A., and Tezcan, M. E. (2021). The relationship between irritability and autism symptoms in children with ASD in COVID-19 home confinement period. Int. J. Clin. Pract. 75:e14742. doi: $10.1111 /$ ijcp. 14742

Uçar, H. N., Çetin, F. H., Türkoğlu, S., Sağliyan, G. A., Çiçek Zekey, Ö, and Yılmaz, Ç (2021). Trauma reactions in children with ADHD during the COVID-19 pandemic: the mediating effect of irritability. J. Loss Trauma [Epub ahead of print].

Velicer, W. F. (1978). Suppressor variables and the semi-partial correlation coefficient. Educ. Psychol. Meas. 38, 953-958. doi: 10.1177/ 001316447803800415

Waite, P., Pearcey, S., Shum, A., Raw, J. A., Patalay, P., and Creswell, C. (2021). How did the mental health symptoms of children and adolescents change over early lockdown during the COVID-19 pandemic in the UK? JCPP Adv. 1:e12009. doi: $10.1111 /$ jcv2.12009

Watson, D., Clark, L. A., Chmielewski, M., and Kotov, R. (2013). The value of suppressor effects in explicating the construct validity of symptom measures. Psychol. Assess. 25:929. doi: 10.1037/a0032781

Weisbrot, D. M., and Ryst, E. (2020). Debate: student mental health matters-the heightened need for school-based mental health in the era of COVID-19. Child. Adolesc. 25, 258-259. doi: 10.1111/camh.12427

Wong, C. W., Tsai, A., Jonas, J. B., Ohno-Matsui, K., Chen, J., Ang, M., et al. (2021). Digital screen time during the COVID-19 pandemic: risk for a further myopia boom? Am. J. Ophthalmol. 223, 333-337. doi: 10.1016/j.ajo.2020.07.034

Worldometer (2020). Total Coronavirus Cases in the World. Available online at: https://www.worldometers.info/coronavirus/ (accessed December 6, 2021)

Xiang, M., Zhang, Z., and Kuwahara, K. (2020). Impact of COVID-19 pandemic on children and adolescents' lifestyle behavior larger than expected. Prog. Cardiovasc. Dis. 63:531. doi: 10.1016/j.pcad.2020.04.013

Conflict of Interest: The authors declare that the research was conducted in the absence of any commercial or financial relationships that could be construed as a potential conflict of interest.

Publisher's Note: All claims expressed in this article are solely those of the authors and do not necessarily represent those of their affiliated organizations, or those of the publisher, the editors and the reviewers. Any product that may be evaluated in this article, or claim that may be made by its manufacturer, is not guaranteed or endorsed by the publisher.

Copyright (๑) 2022 Morgül, Kallitsoglou, Essau and Castro-Kemp. This is an openaccess article distributed under the terms of the Creative Commons Attribution License (CC BY). The use, distribution or reproduction in other forums is permitted, provided the original author(s) and the copyright owner(s) are credited and that the original publication in this journal is cited, in accordance with accepted academic practice. No use, distribution or reproduction is permitted which does not comply with these terms. 